\title{
Direction drainage of supralevator abscess
}

\author{
R. Zinicola ${ }^{1}$ (1) $\cdot$ N. Cracco $^{2}$
}

Received: 5 August 2021 / Accepted: 6 September 2021 / Published online: 1 October 2021

(c) Springer Nature Switzerland AG 2021

\section{Dear Sir,}

We really appreciated the paper of Jeri McFarlane and colleagues on emergency surgical drainage toward the rectal lumen of an acute supralevator abscess (SLA) arising from inter-sphincteric fistula according to Park's principles [1, 2]. SLA is a difficult condition and it is crucial to drain it correctly to avoid complex fistula formation. Most patients with acute anorectal abscesses are given emergency treatment by general surgeons without special experience in proctological disorders. Parks pointed out the importance of the direction of SLA drainage according to the origin of sepsis: the abscess with inter-sphincteric origin should be drained towards the lumen (inwards), whereas those with trans-sphincteric origin should be drained trough the ischioanal fossa (outwards) [2].The principle of inward or outward drainage depending the different origin of sepsis has been adopted by several authors but without formal validation and there is a lack of detailed data on surgical outcome of SLA draining [3]. The ideal form of drainage of acute SLA is still debated [4].We have suggested a simple "skeletal muscle" rule which divides all anorectal abscesses (supralevator, ischiorectal, inter-sphincteric, perianal, submucosal) into two groups according to whether or not the infection has passed through the external sphincter or the levator ani, regardless of the origin of the sepsis. If it has, the abscess should be drained outwards and if not, drainage should be inwards [5]. Magnetic resonance imaging is very accurate in distinguishing between these two groups. Applying the simple "skeletal muscle" rule to magnetic resonance imaging could help the surgeon with limited proctological expertise to manage properly acute SLA.

\section{Declarations}

Conflict of interest All authors declare that they have no conflict of interest.

\section{References}

1. Jeri-McFarlane S, García-Granero A, Gil-Catalan A, CrausMiguel A, Coll-Sastre M, Gamundi-Cuesta M, Ginard-Vincens D, Gonzalez-Argente FX (2021) Surgical strategy for supralevator abscess in Perianal Crohn's disease: emergency surgery and residual complex fistula. Techn Coloproctol (Online 24 May 2021)

2. Parks AG, Gordon PH, Hardcastle JD (1976) A classification of fistula in ano. Br J Surg 63:1-12

3. Zinicola R, Cracco N, Rossi G, Giuffrida M, Giacometti M, Nicholls RJ'(2021) Acute supralevator abscess: the little we know. Ann R Coll Surg Engl (Accepted 30 July 2021)

4. GarcìaGranero A, Sancho-Muriel J, Sanchez-Guillèn L, Alvarez Sarrado E, Fletcher-Sanfeliu D, Frasson M, Valverde-Navarro A, Martinez Soriano F (2018) Simulation of supralevator abscesses and complex fistulas in cadavers: pelvic dissemination and drainage routes. Dis Colon Rectum 61(9):1102-1107

5. Zinicola R (2014) Cracco N (2014) Draining an anal abscess: the skeletal muscle rule. Colorectal Dis 16(7):562

Publisher's Note Springer Nature remains neutral with regard to jurisdictional claims in published maps and institutional affiliations.
R. Zinicola

rzmediterraneo@gmail.com

1 General Surgery Unit, University Hospital Parma, Parma, Italy

2 General Surgery Unit, IRCCS Sacro Cuore Don Calabria Hospital, Negrar, Verona, Italy 